\title{
Determination Of the Effect Of Cooling Rate And Strontium Amount On Eutectic Si Modification Performance Of A356 Alloy Via Casting Simulation
}

 \\ ${ }^{1}$ Material Science and Engineering Department, İzmir Katip Celebi University, Izmir, Turkey \\ ${ }^{2}$ CMS Jant ve Makina San. R\&D Center, Izmir, Turkey \\ *bdogdu@cms.com.tr \\ *Orcid:0000-0003-4110-7341
}

Received: 26 January 2021

Accepted: 2 August 2021

DOI: $10.18466 /$ cbayarfbe. 869010

\begin{abstract}
It is well-known that strontium addition into molten metal as a eutectic modifier increases the elongation and toughness values of the cast parts by refining the eutectic phases. However, when over-modification occurs, porosity increases due to some unwanted physical and chemical reactions that develop within the structure. On the other hand, it has been seen that high cooling rates tend to reduce the porosity of the alloy, decrease grain size and secondary dendrite arm spacing and refine eutectic silicon phase on Al-Si casting alloys. Within the scope of this research, it is aimed to investigate the effects of the cooling rate of cast part and the addition amount of strontium on the silicon modification behavior of Al A356 (AlSi7Mg) alloy parts using casting simulation environment. To examine the effect of strontium amount, $150,250,350$ and 450 parts per million of strontium additions were selected in accordance with the aluminum wheel production limits that given by OEM customers. After the casting session of each $\mathrm{Al}$ A356 composition with different strontium amount by using special designed 5-spoke mold on casting simulation, thermal analysis was done by obtained thermocouple data from casting part's each spoke. Obtained thermal analysis data was interpreted with the casting simulation outputs. Within all aspects, the 150 parts per million strontium addition on Al A356 alloy have been identified as the most useful simulation model in terms of casting performance.
\end{abstract}

Keywords: A356 alloy, casting simulation, cooling rate, eutectic modification

\section{Introduction}

Aluminum (Al)-Silicon ( $\mathrm{Si}$ ) casting alloys as one of the most popular family of the cast Al alloys which have been used in industry for decades, especially for the advantages of their light weight, recyclability and high specific strength [1]. The most common composition of $\mathrm{Al}-\mathrm{Si}$ casting alloy is $\mathrm{A} 356$ ( $\mathrm{Al} 7 \mathrm{Si} 0.3 \mathrm{Mg}$ ) which contains needle-like hard and brittle eutectic Si phase and ductile $\alpha$-Al phase as alloy matrix. This eutectic phase, inside solidified commercially pure (CP) A356 alloy, has a needle-like structure and results an increment on inner stress due to increased stress sharp edges inside microstructure. Modification is a must in order to refine the eutectic $\mathrm{Si}$ phase to obtain finer morphology. Unmodified Si phase inside Al-Si casting alloy degrades tensile strength and fatigue properties of cast part to eliminate this negative effect and increase mechanical properties such as tensile strength, toughness and elongation, eutectic modification and grain refinement procedures have been used for most of the $\mathrm{Al}$ cast parts. This modification can be obtained by either chemically, by using master alloys, and physically by increasing the rate of solidification by extracting the heat energy of alloy with mold adaptations and external cooling channels.

Chemical modifiers are master alloys including $\mathrm{Sr}$, sodium $(\mathrm{Na})$, barium $(\mathrm{Ba})$, calcium $(\mathrm{Ca})$ and europium (Eu) elements used to obtain eutectic modification which avoids eutectic Si growth by the mechanism of impurity induced twinning (IIT) growth and twin plane re-entrant (TPRE) poisoning [2-4]. Besides that ability, $\mathrm{Sr}$ melt treatment increases the $\mathrm{H}$ concentration in the melt. Consequently, Iwahori et.al. investigated that $\mathrm{Sr}$ addition to the melt effects the porosity formation in $\mathrm{Al}-$ $7 \% \mathrm{Si}$ alloys. Also, they proposed that there was a correlation between the observed oxide number and porosity for (Sr) modified A356 alloy [5]. Additionally, besides the benefits of $\mathrm{Sr}$ on modification, it is believed 
that $\mathrm{Sr}$ reduces the surface tension of the molten alloy which may cause to porosity formation with increased wt. $\%$ content [6].

Grain refinement also can be acquired chemically by using master alloy contribution inside $\mathrm{Al}$ melt, such as titanium (Ti), niobium $(\mathrm{Nb})$, beryllium $(\mathrm{Be})$, boron $(\mathrm{B})$ and lanthanum (La) based, by the mechanism of creating potential nucleation sites for $\alpha$-Al dendrites [7]. It is also known that Ti-B master alloys which have been used as a commercial grain refiner, have a chronical problem such as fading and poisoning mechanism, which also has a negative influence on mechanical properties of A356 alloy. As a consequence of higher density of the nucleant $\mathrm{TiB}_{2}$ and $\mathrm{TiAl}_{3}$ particles, than molten $\mathrm{Al}$, settlement of nucleants through the crucible can be observed by the function of time and gravity. This mechanism is known as fading. On the other hand, $\mathrm{TiB}_{2}$ particle surface interface is an energetically favorable site for $\mathrm{Si}$ growth, compared to the Al-matrix grain boundaries. Ti-Si included compound coats $\mathrm{TiAl}_{3}$ surface and degrades the influence of the nucleant that exists in the Ti-B master alloy, based on Sigworth and Guzowaski's work [8]. On both fading and poisoning effect, grain refinement efficiency decreases dramatically, which have deleterious consequences on strength and toughness of the cast part [9]. Commercially, foundries have been using $\mathrm{Sr}$ and Ti-B based master alloys for eutectic modification and grain refinement respectively, on the process of melt treatment before actual casting stage.

Moreover, heat extraction velocity from molten metal can influence the temperature gradient in the mold, thus, solidification rate of the alloy itself, and is one of the most important variable which influences microstructure and mechanical characteristic of castings. At elevated solidification rates, more $\alpha$-Al dendrites with smaller arm spacing will be formed, resulting in lower and more uniform distribution of shrinkage porosity due to enhanced mass feeding [1012]. In addition, high cooling rate ensures eutectic Si phase refining by blocking the growth of eutectic Si which greatly affects mechanical properties positively [13].

Ferdian et al. proposed that to determine the optimum amount of eutectic modification, the needed eutectic depression must be at least $7{ }^{\circ} \mathrm{C}$ which is slightly higher than the value previously proposed by Apelian et al. as $5.5^{\circ} \mathrm{C}$ [14]. Additionally, the authors suggested that the only values of solidification rate higher than $0.7{ }^{\circ} \mathrm{C} / \mathrm{s}$ relate to sufficient modification of A356 alloy in either sand or metallic molds.

The innovative approach of this study is to investigate the effect of $\mathrm{Sr}$ content and cooling rate on $\mathrm{Si}$ modification with the help of casting simulation analysis. In order to execute detailed investigations on melt treatment performances, thermal analysis technique has been examined for determination of melt treatment level and quality assessment of casting. Normally, thermal analysis examination proceeds by extracting analog data from molten metal, at the time of where molten metal solidifies, and transforming the data into digital one on an analog to digital converter device. Instead of this standard procedure, casting simulation's virtual thermocouple's data was used in this work. By obtained $\mathrm{T} / \mathrm{t}$ graphs, $\mathrm{T}_{\text {nucleation }}\left(\mathrm{T}_{\mathrm{n}}\right), \mathrm{T}_{\text {minimum }}\left(\mathrm{T}_{\mathrm{m}}\right)$ and $T_{\text {growth }}\left(T_{g}\right)$ temperatures can be analyzed by first derivate method of $\mathrm{T} / \mathrm{t}$ graph itself, for eutectic modification which is dealt with in the current paper. Finally, the effects of $\mathrm{Sr}$ amount and cooling rate are summarized by comprising the whole results consisting of macroporosity formation, eutectic grain radius, $\mathrm{Sr}$ macrosegregation and thermal analysis data outcomes.

\section{Materials and Methods}

Firstly, a mold design was studied on Catia V5 CAD software, by considering the cooling rate differences on each spoke. The five spoke mold was designed on two different section volume by referencing of middle point of the casting part, as it seems on Figure 1. That section differences were designed to obtain different thermal gradient on the same mold. Therefore, on the thick section part, two air cooling nozzle holes were implemented to get much higher cooling rates due to obtain different cooling rates on edge to edge (higher values on thick section, lower values on thin section). After the design step, the CAD mold was appended on Magmasoft casting simulation software. $4 \mathrm{~mm}$ tetrahedral mesh was implied on whole cast and mold data. To examine the efficacy of $\mathrm{Sr}$ contribution, thanks to material Jmat Pro database of Magmasoft, thermodynamic calculations were made for 150, 250, 350 and $450 \mathrm{ppm}$ of $\mathrm{Sr}$ addition. Lever equation was used for each $\mathrm{Sr}$ concentration. Based on the standard casting parameters $\left(700^{\circ} \mathrm{C}\right.$ molten metal temperature, $350^{\circ} \mathrm{C}$ mold temperature), numbers of experiments were designed through the whole process to correlate to solidification of A356 alloy by real casting examinations. Nevertheless, in order to observe only the eutectic modification performance of each casting version on the casting simulation, grain refiner was not defined on elemental composition of A356 alloy, so that data noise that may be occurred by thermodynamic calculation of Ti and B was eliminated. Detailed casting simulation parameters data are given in Table 1 . Thermal regime of the mold and cooling curves of the middle point of each spoke were obtained by virtual thermocouples. By these thermocouple data, $T_{n}, T_{m}$ and $\mathrm{T}_{\mathrm{g}}$ were considered to compare the effect of cooling rate and $\mathrm{Sr}$ amount on eutectic modification performance for each spoke. As a final step, macroporosity formation, eutectic grain radius, $\mathrm{Sr}$ macrosegregation and thermal analysis data outcomes were examined based on each $\mathrm{Sr}$ addition and cooling behavior of each spoke of the cast part. 
Table 1. Casting Parameters.

\begin{tabular}{|c|c|c|}
\hline Parameter & Material & Specification \\
\hline $\begin{array}{l}\text { Cast Part } \\
\text { Temperature }\end{array}$ & $\begin{array}{l}\mathrm{Al} 7 \mathrm{Si} 0.3 \mathrm{Mg} \\
\quad(\mathrm{A} 356)\end{array}$ & $700^{\circ} \mathrm{C}$ \\
\hline $\begin{array}{l}\text { Modifier } \\
\text { Element }\end{array}$ & $\mathrm{Sr}$ & $\begin{array}{c}150,250,350 \text { and } 450 \\
\mathrm{ppm}\end{array}$ \\
\hline $\begin{array}{c}\text { Mold } \\
\text { Temperature }\end{array}$ & $\begin{array}{c}\mathrm{X} 40 \mathrm{CrMoV} \\
5-1(\mathrm{H} 13)\end{array}$ & $350^{\circ} \mathrm{C}$ \\
\hline $\begin{array}{l}\text { Heat Transfer } \\
\text { Between Cast } \\
\text { Part and Mold }\end{array}$ & - & $\begin{array}{c}1-548^{\circ} \mathrm{C} \# 1000 \\
\mathrm{~W} / \mathrm{m}^{2} . \mathrm{K} \\
548-613^{\circ} \mathrm{C} \# \text { linear } \\
\text { increment } \\
613-1000^{\circ} \mathrm{C} \# 2700 \\
\mathrm{~W} / \mathrm{m}^{2} . \mathrm{K} \\
\end{array}$ \\
\hline $\begin{array}{c}\text { Cooling } \\
\text { Channel (x2) }\end{array}$ & $\begin{array}{l}\text { Air }(6 \text { bar, } \\
\left.20^{\circ} \mathrm{C}\right)\end{array}$ & $1450 \mathrm{~W} / \mathrm{m}^{2} . \mathrm{K}$ \\
\hline $\begin{array}{c}\text { Heat Transfer } \\
\text { Between Mold } \\
\text { and Medium }\end{array}$ & - & $\begin{array}{c}\varepsilon=0.3 \\
h=20 \mathrm{~W} / \mathrm{m}^{2} . \mathrm{K}\end{array}$ \\
\hline $\begin{array}{c}\text { Heat Transfer } \\
\text { Between Cast } \\
\text { Part and } \\
\text { Medium }\end{array}$ & - & $\begin{array}{c}\varepsilon=0.8 \\
h=20 \mathrm{~W} / \mathrm{m}^{2} . \mathrm{K}\end{array}$ \\
\hline Die Coating & Dycote34 & Thickness $=0.1 \mathrm{~mm}$ \\
\hline $\begin{array}{l}\text { Molten Metal } \\
\text { Inlet Mass } \\
\text { Flow Rate }\end{array}$ & $\begin{array}{l}\text { Al7Si0.3Mg } \\
\quad(\mathrm{A} 356)\end{array}$ & $0.285 \mathrm{gr} / \mathrm{s}$ \\
\hline
\end{tabular}

\subsection{Cooling Design of the Mold}

Cooling system of the mold was designed for obtaining various cooling rates on each spoke of the casting part. For purpose of obtaining different solidification rate from each spoke, mold thickness difference and cooling channel implementation were applied to the mold on Catia V5 CAD software. Thanks to bulk mold mass on thick section, it was thought that thick section will absorb more heat by relying on the principle of $\mathrm{Q}=\mathrm{mc} \Delta t$. Conversely, it was seen that thin section's temperature was increased due to decreased mold mass on that area, as indicated in Figure 2. On the other hand, implemented external cooling channels extract the heat of the mold, so that, heat flow through casting part to mold can be forced.

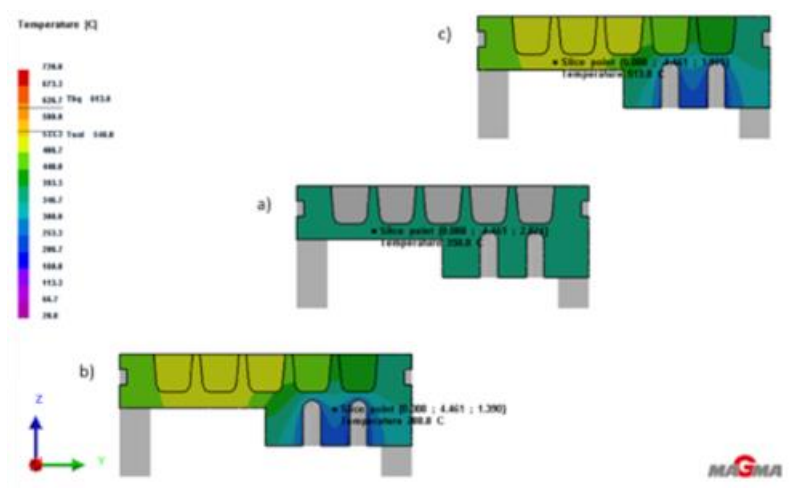

Figure 2. Temperature Scale of zy plane section of the a) $\mathrm{T}=350^{\circ} \mathrm{C}$ at $\mathrm{t}=0$, b) $\mathrm{T}=288.8^{\circ} \mathrm{C}$ at $\mathrm{t}=$ final (Thick section with cooling channel implementation.) and c) $=$ $513^{\circ} \mathrm{C}$ at $\mathrm{t}=$ final (Thin section).

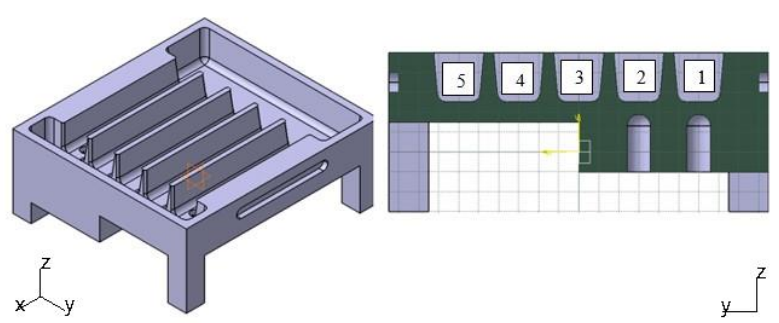

Figure 1. a) Isometric view, and b) mid-section of the mold, where cooling channel hubs and spoke numbers can be seen.

\section{Results and Discussion}

In this part, the whole experimental results are analyzed in 5 different perspectives as Cooling Design of the Mold, Eutectic Grain Radius, Sr Macrosegregation, Shrinkage Porosity, and Thermal Analysis.
As it seems in Figure 3., spoke 1 has solidified primarily on cast part. After the solidification of spoke 1, spoke 5 tend to become solid on $\mathrm{t}=65 \mathrm{~s}$. And then, thermal gradient difference between thick section and thin section of the mold was exposed, as spoke 2, 3 and 4 has is solidified, respectively. It is seen that, while the solidification has been proceeding, the warmest part of the casting where the molten metal get poured into the mold and where solidification occurred lastly, has shrunk because of density difference between molten alloy and solidified alloy. The warmer the area, higher possibility to get shrank. However, that bulk shrinkage formation is acceptable on design criteria since only the spokes of the casting part were taken into consideration. 


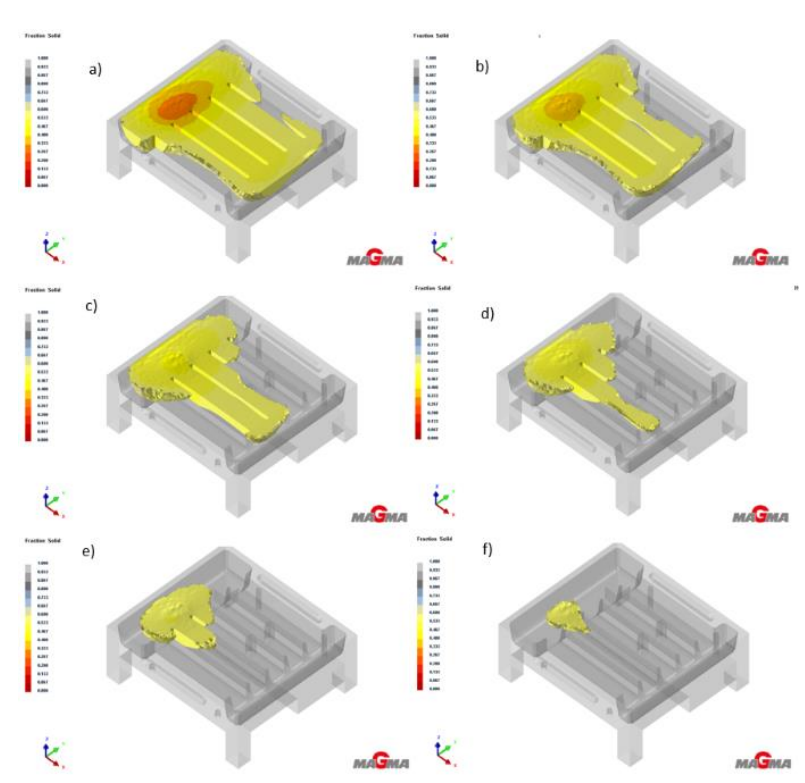

Figure 3. Solidification Sequence of A356 Alloy on Magmasoft Casting Simulation at a) $65 \mathrm{~s}$, b) $75 \mathrm{~s}$, c) $95 \mathrm{~s}$, d) $115 \mathrm{~s}$, e) $135 \mathrm{~s}, \mathrm{f}) 175 \mathrm{~s}$ as a result of $\%$ fraction solid.

\subsection{Eutectic Grain Radius}

On casting simulations, eutectic grain radius (EGR) module shows amount of the eutectic phase formation between dendrites. In the scope of the work of Ferdian et al., eutectic Si shape and size on Al-Si alloys are directly related with cooling rate and the amount of eutectic growth restrictor element, like $\mathrm{Sr}, \mathrm{Na}$ [15].

In Figure 4, EGR values tend to decrease on every step of $\mathrm{Sr}$ addition on spoke 4, except of other four spoke on $150 \mathrm{ppm} \mathrm{Sr}$ casting setup. It can be interpreted that even if on the spoke 4, which has lowest solidification rate, $150 \mathrm{ppm}$ Sr addition has the ability to modify eutectic $\mathrm{Si}$. After $250 \mathrm{ppm} \mathrm{Sr}$ addition, overall eutectic radius increment has been seen. On the following compositions of 350 and $450 \mathrm{ppm} \mathrm{Sr}$ addition, overall EGR values have a tendency to decrease linearly but not remarkably.

\subsection{Sr Macrosegregation}

In the consideration of a solid solution, solvent atoms have the possibility to tend to freeze before the solute atoms, which causes a composition gradient in molten alloy under non-equilibrium conditions [16]. The thermal and compositional condition responsible for this cellular micro and macrosegregation is named as constitutional undercooling. Cooling characteristic related segregation values are listed below.

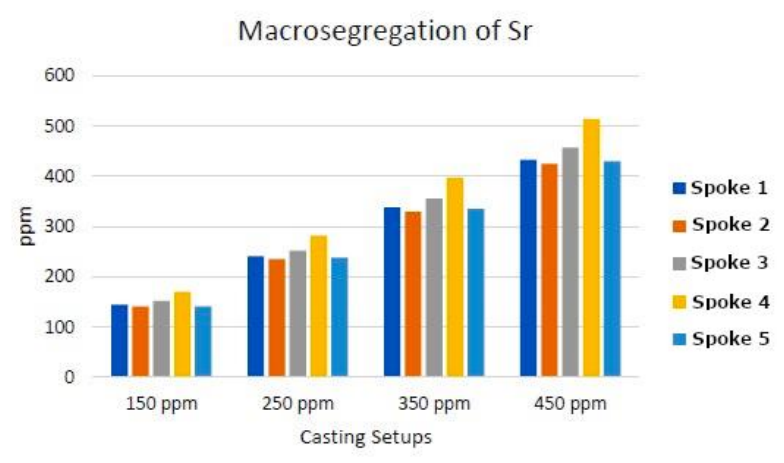

Figure 5. Macrosegregation value schematic in terms of ppm.

Based on simulation data, Sr macrosegregation is highly caused by solidification rate. There might be some other reasons such as oxide film density, filling properties of molten metal into the mold and etc. Therefore, because of the linear increment on the values of macrosegregation of $\mathrm{Sr}$ in terms of ppm, it can be said that, theoretically the Sr addition amount on A356 alloy does not have any impact, as it seems in Figure 5, the ppm difference ratio between each spoke is different.

\subsection{Shrinkage Porosity}

According to Nampoothiri et al., the addition of $\mathrm{Sr}$ triggers the porosity formation in the interdendritic region of alloy which terminates the advantageous influence obtained by morphological transformation of eutectic Si [12]. Also, it is known that lack of feeding is a cause for macroshrinkage during solidification where the density of alloy has change by heat extraction from melt. Macroshrinkage can be avoided by rapid and directional solidification through the whole part. Interdendritic feeding is the key for the solution of macroporosity. As it was indicated in Figure 6, minimum porosity formation was obtained on $150 \mathrm{ppm}$ $\mathrm{Sr}$ addition (Figure 6b). Conversely, maximum porosity formation was observed on $250 \mathrm{ppm} \mathrm{Sr}$ included A356 alloy (Figure 6c)

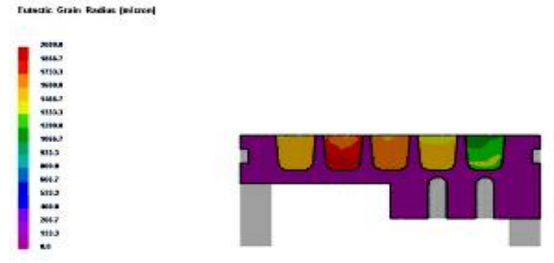

$\stackrel{\jmath}{\longrightarrow}$

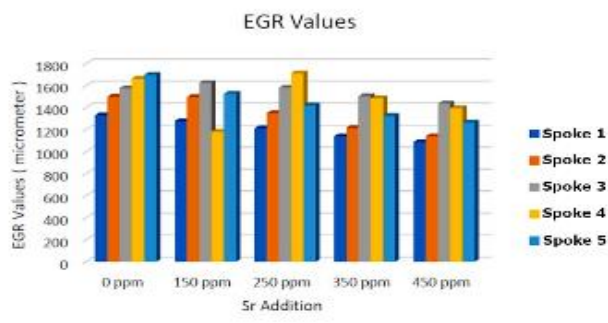

Figure 4. EGR value representation based on $\mathrm{Sr}$ amount. 


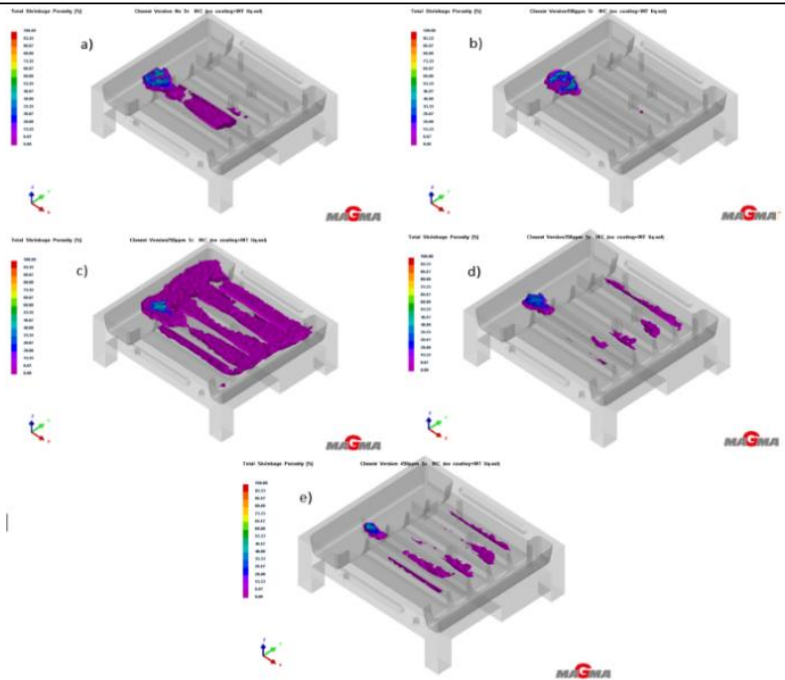

Figure 6. Total Shrinkage Porosity formation of a) CP. A356, b) $150 \mathrm{ppm} \mathrm{Sr}$, c) $250 \mathrm{ppm} \mathrm{Sr}$, d) $350 \mathrm{ppm} \mathrm{Sr}$ and e) $450 \mathrm{ppm} \mathrm{Sr}$.

\subsection{Thermal Analysis}

Thermal analysis on Al-Si alloys has critical importance on defining the solidification path of the alloy itself. To specify the $\alpha \mathrm{Al}$ dendrite solidification temperature, eutectic $\mathrm{Si}$ nucleation temperature $\left(\mathrm{T}_{\mathrm{n}}\right)$, eutectic minimum temperature $\left(T_{m}\right)$, eutectic growth temperature $\left(\mathrm{T}_{\mathrm{g}}\right)$ and the other intermetallic phases such as $\beta$ $\mathrm{Al}_{5} \mathrm{FeSi}, \pi-\mathrm{Al}_{8} \mathrm{FeMg}_{3} \mathrm{Si}_{6}$ and $\beta-\mathrm{Mg}_{2} \mathrm{Si}$, derivative point analysis is necessary. Ferdian et al. suggested that eutectic depression $\left(T_{g}-T_{m}\right)$ should be examined to observe eutectic modification [15]. The only way for reliable examination is derivative curve analysis.

The thermal analysis curves were obtained from virtual thermocouples on Magmasoft software. For each spoke and $\mathrm{Sr}$ addition, $\mathrm{T}_{\mathrm{n}}, \mathrm{T}_{\mathrm{m}}$ and $\mathrm{T}_{\mathrm{g}}$ temperatures have been extracted from these curves. In Figure 7, T/t curve (blue dots) and its derivative (green dots) of spoke 5 of CP. A356 casting setup was indicated, as an example.

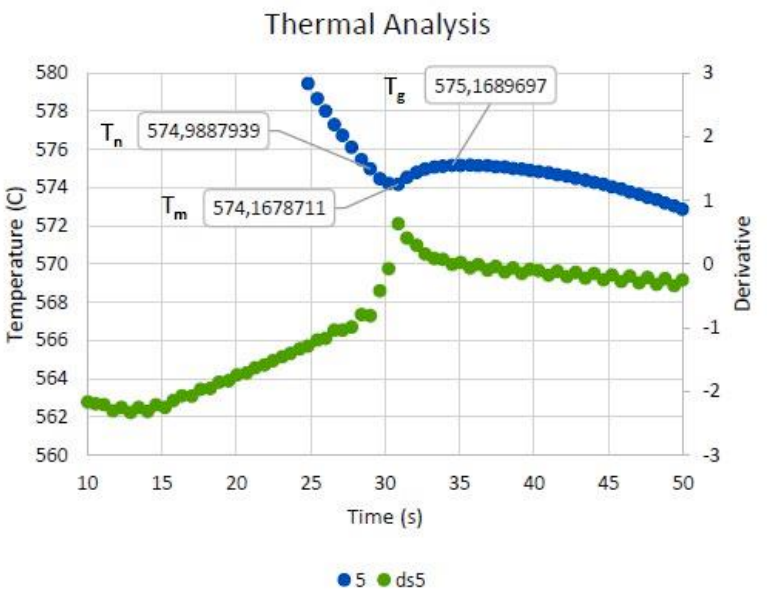

Figure 7. Thermal analysis of spoke 5, (T/t curve with blue dots and its derivative curve with green dots) on CP. A356.
Based on $\mathrm{T} / \mathrm{t}$ graphs of all the casting simulation setups, it can be clearly said that $\mathrm{Sr}$ addition on A356 alloy has a direct influence on the eutectic formation temperatures. It decreases eutectic nucleation temperature up to $560{ }^{\circ} \mathrm{C}$ in overall, without considering the effect of cooling rate. Up to $450 \mathrm{ppm}$ from $150 \mathrm{ppm}$ $\mathrm{Sr}$ addition, just slight differences exist. On the other hand, cooling rate calculations have been made based on Equation 1. Negative slope of T/t curve between the point of where $\alpha \mathrm{Al}$ dendrites start to solidify and the eutectic nucleation spot, has been calculated. On Table 2 , it can be seen that aimed cooling rate difference through the spokes has obtained. By this variation, it is obvious that cooling rate has a strong influence on eutectic formation mechanism, according to simulation calculations. When liquid molten alloy is solidified at an elevated solidification rate, the actual supercooling of the solidified alloy is large and thus the nucleation rate of eutectic phase is increased.

Both $T_{n}$ and eutectic depression undercooling mechanisms are important to obtain modified eutectic Si in microstructure of Al-Si hypoeutectic alloys. The importance of undercooling of nucleation has been proposed in the literature. It is mentioned that the decreased $T_{n}$ is attributed to the potential nucleation sites (AlP) poisoned by $\mathrm{Sr}$ [17-20]. Therefore, the decreased $T_{n}$ also suggests that the required nucleation undercooling is increased. This also shows that the addition of $\mathrm{Sr}$ ensures the nucleation of the eutectic phase more difficult at high temperature. The decrease on the temperature of $\mathrm{Tm}$ indicates the present undercooling of the melt is increased when more of nucleation events occur.

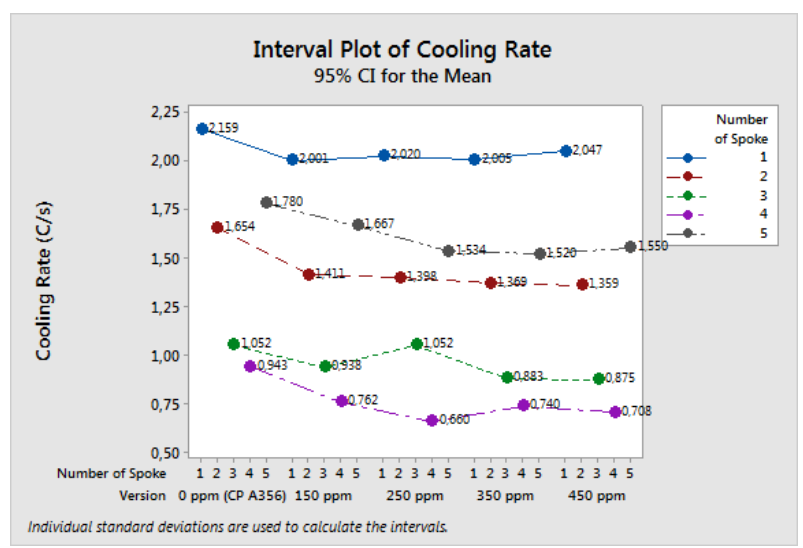

Figure 8. Representation of Cooling Rate change according to $\mathrm{Sr}$ addition and spoke. 
Table 2. Thermal Analysis Values of Casting Simulation.

\begin{tabular}{|c|c|c|c|c|c|c|}
\hline \multirow{2}{*}{ 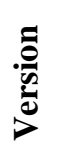 } & \multirow{2}{*}{ Temperature $\left({ }^{\circ} \mathrm{C}\right)$} & \multicolumn{5}{|c|}{ Spoke Number } \\
\hline & & 5 & 4 & 3 & 2 & 1 \\
\hline \multirow{4}{*}{$\begin{array}{l}0 \\
\stackrel{2}{u} \\
\dot{u} \\
\dot{u}\end{array}$} & $\mathbf{T}_{\mathbf{n}}$ & 574.4 & 575.5 & 576.0 & 577.0 & 574.7 \\
\hline & $\mathbf{T}_{\mathbf{m}}$ & 574.2 & 574.8 & 574.6 & 574.3 & 573.8 \\
\hline & $\mathbf{T}_{\mathbf{g}}$ & 575.1 & 575.4 & 575.1 & 575.0 & 574.9 \\
\hline & Cooling Rate $\left({ }^{\circ} \mathrm{C} / s\right)$ & 1.7 & 0.9 & 1.0 & 1.6 & 2.1 \\
\hline \multirow{4}{*}{  } & $\mathbf{T}_{\mathbf{n}}$ & 565.8 & 565.6 & 565.9 & 563.1 & 560.4 \\
\hline & $\mathbf{T}_{\mathbf{m}}$ & 560.4 & 565.5 & 562.3 & 560.3 & 557.3 \\
\hline & $\mathbf{T}_{\mathrm{g}}$ & 560.7 & 565.8 & 562.5 & 559.8 & 556.2 \\
\hline & Cooling Rate $\left({ }^{\circ} \mathrm{C} / s\right)$ & 1.6 & 0.7 & 0.9 & 1.4 & 2.0 \\
\hline \multirow{4}{*}{ 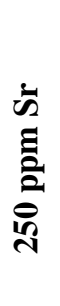 } & $\mathbf{T}_{\mathbf{n}}$ & 562.9 & 564.9 & 562.7 & 560.8 & 558.8 \\
\hline & $\mathbf{T}_{\mathbf{m}}$ & 558.1 & 563.1 & 560.0 & 558.1 & 554.7 \\
\hline & $\mathbf{T}_{\mathbf{g}}$ & 560.5 & 565.3 & 561.6 & 557.5 & 554.7 \\
\hline & Cooling Rate $\left({ }^{\circ} \mathrm{C} / s\right)$ & 1.5 & 0.6 & 1.0 & 1.3 & 2.0 \\
\hline \multirow{4}{*}{$\begin{array}{c}\dot{n} \\
\stackrel{n}{2} \\
\stackrel{n}{2}\end{array}$} & $\mathbf{T}_{\mathbf{n}}$ & 560.5 & 566.1 & 565.3 & 563.1 & 561.7 \\
\hline & $\mathbf{T}_{\mathbf{m}}$ & 558.0 & 563.1 & 559.9 & 558.1 & 554.9 \\
\hline & $\mathbf{T}_{\mathrm{g}}$ & 560.4 & 565.3 & 561.0 & 557.3 & 554.7 \\
\hline & Cooling Rate $\left({ }^{\circ} \mathrm{C} / s\right)$ & 1.5 & 0.7 & 0.8 & 1.3 & 2.0 \\
\hline \multirow{4}{*}{ 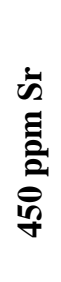 } & $\mathbf{T}_{\mathbf{n}}$ & 562.0 & 566.1 & 564.1 & 562.6 & 558.7 \\
\hline & $\mathbf{T}_{\mathbf{m}}$ & 558.3 & 563.1 & 559.9 & 557.9 & 554.8 \\
\hline & $\mathbf{T}_{\mathrm{g}}$ & 560.5 & 565.3 & 561.6 & 557.2 & 554.7 \\
\hline & Cooling Rate $\left({ }^{\circ} \mathrm{C} / s\right)$ & 1.5 & 0.7 & 0.8 & 1.3 & 2.0 \\
\hline
\end{tabular}




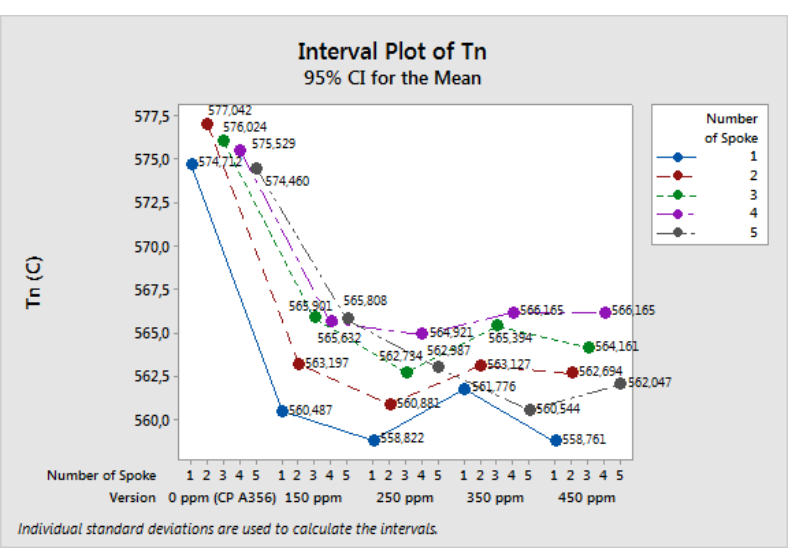

Figure 9. Representation of $\mathrm{T}_{\mathrm{n}}$ change according to $\mathrm{Sr}$ addition and spoke.

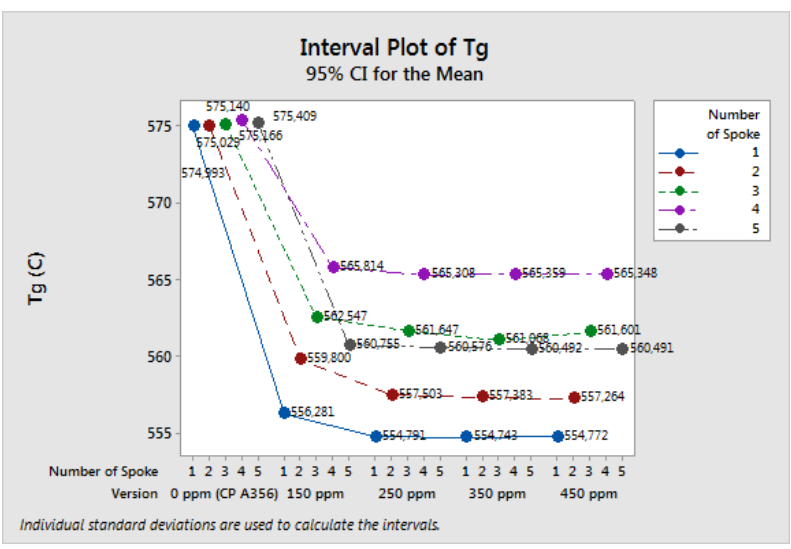

Figure 10. Representation of $\mathrm{T}_{\mathrm{g}}$ change according to $\mathrm{Sr}$ addition and spoke.

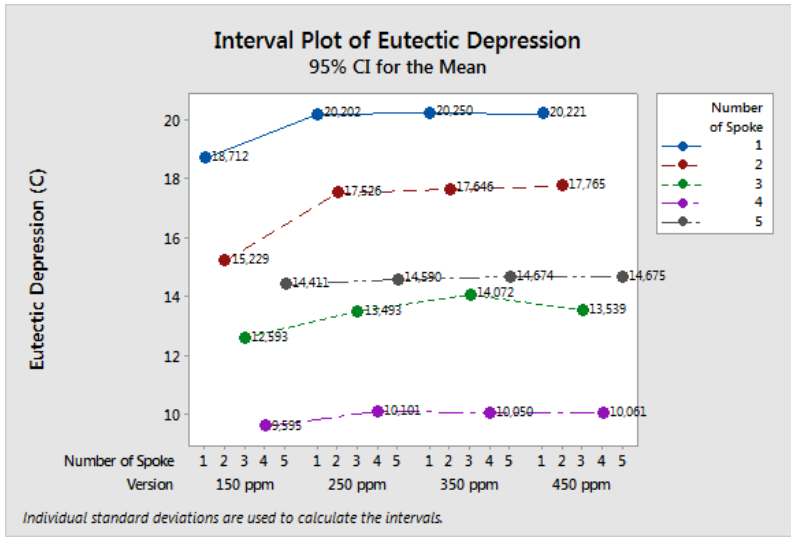

Figure 11. Representation of Eutectic Depression change according to $\mathrm{Sr}$ addition and spoke.

Whole data was analyzed with the help of Minitab 18 software. Figure 8-11 show the Cooling Rate, $T_{n}, T_{g}$ and Eutectic Depression changes according to $\mathrm{Sr}$ addition and spoke number, respectively. In Figure 8, it was seen that $\mathrm{Sr}$ addition affected the solidification rate of each casting part even if mold and molten metal temperatures are exactly same for all versions. This effect may have occurred due to thermodynamic reaction calculations during solidification of the alloy. In Figure 9 and Figure 10 , minimum $\mathrm{T}_{\mathrm{n}}$ and $\mathrm{T}_{\mathrm{g}}$ were achieved, respectively, for $250 \mathrm{ppm} \mathrm{Sr}$ contribution. For the addition amount higher than $250 \mathrm{ppm}$, the increment was observed for the $T_{n}$ at Figure 9. It was proven that solidification rate of alloy has a significant impact on $T_{n}$ and $T_{g}$. Moreover, it was indicated on Minitab graph that 250 ppm $\mathrm{Sr}$ addition is influenced by the Eutectic Depression mechanism mostly which was represented in Figure 11. However, it was also shown that there was no significant change more than $250 \mathrm{ppm}$ Sr addition.

\section{Conclusions}

On foundry applications, casting simulations takes critical role due to ability and advantages of detecting casting defects, solidification path of alloy and other major parameters before actual casting process. Thus, it is also possible to predict $\mathrm{Sr}$ addition and cooling rate's association on to eutectic modification thanks to accessible modules of Magmasoft Software.

As a result, it can be concluded that;

- With correct parameters of heat transfer between cast part, mold and medium, composition properties and meshing precision, reasonable results can be obtained. Also, it was seen that thermal analysis studies can be proceeded as computer-based, instead of real-time casting work.

- Theoretical Eutectic Grain Radius (EGR) calculations showed that $\mathrm{Sr}$ addition decreases the eutectic density between dendrites. On spoke 4, 150 ppm $\mathrm{Sr}$ has proceeded very well due to color representation although it has lowest cooling rate. On wheel casting, low cooling rates can be observed on hub section. It is important to obtain eutectic modification even these kind of areas on casting. So that, it is reasonable that $150 \mathrm{ppm} \mathrm{Sr}$ can be a good choice for foundry applications on hypoeutectic Al-Si casting alloys.

- Distribution of macrosegregation of $\mathrm{Sr}$ on each spoke can be seen on the related Magmasoft module. The effect of cooling rate on segregations are significantly observable. Sr amount just only changes the mean value of deviation.

- Shrinkage porosity formation has dramatically increased on $250 \mathrm{ppm} \mathrm{Sr}$ addition. Correlation studies are necessary to prove that claim.

- Thermal analysis results show that the maximum development has occurred on 150 ppm Sr. After that, undercooling on eutectic formation temperatures tend to increase with just a lower ratio. Even if the maximum improvement on modification has obtained by $250 \mathrm{ppm}$ Sr based on eutectic depression data, due to maximum porosity level observation on that composition, theoretical delimitation has obtained. $150 \mathrm{ppm} \mathrm{Sr}$ addition on A356 alloy seems to be best solution for eutectic modification. 
- According to Ferdian et al, minimum eutectic depression limit has obtained as $7^{\circ} \mathrm{C}$, and minimum cooling rate has mentioned as $0.7^{\circ} \mathrm{C} / \mathrm{s}$, for optimum eutectic modification. It can be concluded that, minimum required modification can be observed even on spoke 4 which has lowest cooling rate among all spokes of casting part. Simulation data has given eutectic depression values more than $7^{\circ} \mathrm{C}$ (Minimum value was obtained on spoke 4, $150 \mathrm{ppm}$ Sr level as $\left.9,995^{\circ} \mathrm{C}\right)$.

- It was also exposed that cooling rate and $\mathrm{Sr}$ addition correlation can only get done by further real casting comparison with same setup. Actual microstructure and mechanical properties result such as eutectic $\mathrm{Si}$ aspect ratio and yield-tensile strength and elongation results are noteworthy to consider.

\section{Acknowledgments}

This work was co-supported by Tübitak 2209-B Industry/Undergraduate Thesis Support Programme and also by CMS Jant ve Makina San. R\&D Center.

\section{Author's Contributions}

Batuhan Doğdu: Drafted and wrote the manuscript, performed the experiment and result analysis.

Ugur Aybarç: Assisted in analytical analysis on the structure, supervised the experiment's progress, result interpretation and helped in manuscript preparation.

Serkan Gündoğdu: Assisted in analytical analysis and helped in manuscript preparation.

Onur Ertuğrul: Assisted in analytical analysis on the structure, supervised the experiment's progress, result interpretation and helped in manuscript preparation.

\section{Ethics}

There are no ethical issues after the publication of this manuscript.

\section{References}

1. Sigworth, G. K., Fundamentals Of Solidification In Aluminum Castings. 2014. International Journal of Metalcasting; 8: 7-20.

2. Pramod, Ravikirana, A. K. Prasada Rao, Murty B. S., Bakshi S. R. 2016. Effect of Sc addition and T6 aging treatment on the microstructure modification and mechanical properties of A356 alloy, Materials Science and Engineering: A; 674:438-450.

3. Lu, S Z., Hellawell 1987. A. The mechanism of silicon modification in aluminum-silicon alloys: Impurity induced twinning. Metallurgical and Materials Transactions A, 18:1721-1733.

4. Hanna, M.D., Lu, SZ. \& Hellawell 1984. A. Modification in the aluminum silicon system Metallurgical and Materials Transactions A; 15, 459-469.
5. Iwahori, H., Yonekura, K., Yamamoto, Y., Nakamura, M., 1990. Occuring Behaviour Of Porosity And Feeding Capabilities Of Sodium And Strontium Modified Al-Si Alloys. AFS Transactions; 98:167-173.

6. Fang, Q. T., Granger, D. A. 1989. Porosity Formation In Modified And Unmodified A356 Alloy Castings. Transactions of the American Foundry Society; 97.10: 9891000.

7. Murty B. S., Kori S. A. \& Chakraborty M. 2002. Grain refinement of aluminium and its alloys by heterogeneous nucleation and alloying. International Materials Reviews; 47:1, 3-29

8. Sigworth G.K. and Guzowski M.M. 1985. Grain refining of Hypo-eutectic Al-Si Alloys. AFS Transactions; 93:90712

9. Kori, S. A., Auradi V., Murty, B. S.; Chakraborty, M. 2004. Poisoning and fading mechanism of grain refinement in Al-7Si alloy Proceedings of $3 r d$ International Conference on Advanced Materials Processing (ICAMP-3); pp. 387-393.

10. Zhang L.Y., Jiang A Y.H., Ma Z., Shan S.F., Jiab Y.Z., Fan C.Z., Wang W.K. 2008. Effect of Cooling Rate on Solidified Microstructure and Mechanical Properties of Aluminium-A356 Alloy. Journal of Materials Processing Technology; 207:107-111

11. James G. Conley, Julie Huang, Jo Asada, Kenji Akiba, 2000. Modeling the Effects of Cooling Rate, Hydrogen Content, Grain Refiner and Modifier on Microporosity Formation In Al A356 Alloys. Materials Science and Engineering; 285:49-55.

12. Tiryakioğlu, M., Campbell, J., Alexopoulos, N. D. 2009. On the Ductility of Cast Al-7 Pct Si-Mg Alloys. Metallurgical and Materials Transactions A; 40(4):10001007.

13. Eskin D, Du Q, Ruvalcaba D. 2005. Experimental Study of Structure Formation in Binary Al-Cu Alloys at Different Cooling Rates. Materials Science and Engineering A; 404: $1-10$.

14. Liao H C, Sun Y, Sun G X. 2002. Correlation Between Mechanical Properties and Amount of Dendritic A-Al Phase in As-Cast Near-Eutectic Al-11.6\% Si Alloys Modifies with Strontium. Material Science and Engineering A; 335:62-66.

15. Ferdian, D., Lacaze, J., Lizarralde, I., Niklas, A., \& Fernandez-Calvo, A. I. 2013. Study of The Effect of Cooling Rate on Eutectic Modification in A356 Aluminium Alloys. Materials Science Forum; 765:130134.

16. K. Nogita; H. Yasuda; K. Yoshida; K. Uesugi; A. Takeuchi; Y. Suzuki; A.K. Dahle 2006. Determination of strontium segregation in modified hypoeutectic Al-Si alloy by micro-X-ray fluorescence analysis. Scripta materialia; 55(9), 787-790.

17. Stuart D. McDonald; Kazuhiro Nogita; Arne K. Dahle 2006. Eutectic grain size and strontium concentration in hypoeutectic aluminium-silicon alloys. Journal of alloys and compounds; 422(1-2), 0-191.

18. Sumanth Shankar; Yancy $W$ Riddle; Makhlouf $M$ Makhlouf 2004. Nucleation mechanism of the eutectic 
Celal Bayar University Journal of Science

Volume 17, Issue 3, 2021, p 275-283

Doi: $10.18466 /$ cbayarfbe. 869010

phases in aluminum-silicon hypoeutectic alloys. Acta Materialia 52.15; 4447-4460.

19. Nogita, K., McDonald, S. D., \& Dahle, A. K. 2004. Solidification mechanisms of unmodified and strontium-modified hypereutectic aluminium-silicon alloys. Philosophical Magazine; 84(17), 1683-1696.

20. McDonald, S.D., Dahle, A.K., Taylor, J.A. et al. 2004. Eutectic grains in unmodified and strontium-modified hypoeutectic aluminum-silicon alloys. Metallurgical and materials transactions A;35(6), 1829-1837. 